\title{
Analysing Teacher Knowledge for Technology Use among Secondary Teachers Teaching Chinese as a Foreign Language (CFL) in Australia
}

\author{
Yueying Zeng ${ }^{1, *}$ \\ ${ }^{1}$ School of Languages and Cultures, University of Queensland, Australia \\ *Correspondence: School of Languages and Cultures, University of Queensland, Australia. E-mail: \\ uqyzeng4@uq.edu.au
}

Received: December 20, 2021

Accepted: January 7, 2022 Online Published: January 18, 2022

doi:10.5430/jct.v11n2p15

URL: https://doi.org/10.5430/jct.v11n2p15

\begin{abstract}
Technology has normalised education and promoted teaching and learning activities. However, not all teachers effectively integrate technology into their instruction. Prior studies indicate that teacher knowledge impacts such integration. This study examines technology use among teachers teaching Chinese as a foreign language in Australian secondary schools. Specially, it investigates (a) what teacher knowledge affects technology, (b) how CFL perceive their knowledge, and (c) how to effectively develop teacher knowledge. The findings suggest that technological knowledge (TK) strongly influences CFL instructors' technology use, and these instructors were more confident in their non-technological knowledge than their technology-related knowledge. The finding regarding relationships between knowledge constructs should shed light on knowledge development for teacher education. Hence, this study contributes to teacher training in Australian secondary schools.

Keywords: technology use in education, TPACK, Chinese as a foreign language (CFL), secondary schools, teacher education

\section{Introduction}

In the digital era, technologies are widely adopted as instructional tools in education. Those widely used e-tools can effectively enhance instructional outcomes, such as improving student motivation and providing new learning environments. Despite their normalisation and perceived benefits, not all teachers are keen on integrating technology to improve educational outcomes. Prior research has indicated that teacher knowledge has impacted instructors' technology use (Rohaan et al., 2012; Voogt et al., 2013). Studies have investigated how teacher knowledge affects technology use (Raper, 2018), what specific knowledge affects such use (Raygan \& Moradkhani, 2020), and how to develop teacher knowledge to promote technology integration (Kainat et al., 2021). However, very few of them, if not none, have examined such problems in the context of Chinese as a foreign language (CFL) in Australian secondary schools. Nonetheless, CFL is a hot topic in Australia and the globe. Hence, this study fills the gap by investigating what teacher knowledge affects technology use, how CFL teachers perceive their knowledge, and how to promote teacher training in Australian secondary schools.
\end{abstract}

\section{Literature Review}

Teacher knowledge has been a long-established variable for educators' classroom technology use. Several investigations note it as the strongest predictor of technology integration (Aslan \& Zhu, 2017; Ertmer et al., 2012). Previous literature usually employs the Technology Pedagogical Content Knowledge (TPACK) theory to investigate teacher knowledge required to integrate technology in instruction (Joo et al., 2018; Raper, 2018; Santika et al., 2021; Yang et al., 2019). According to the theory, teacher knowledge includes content knowledge (CK), pedagogical knowledge (PK), technological knowledge (TK), pedagogical content knowledge (PCK), technological content knowledge (TCK), technological pedagogical knowledge (TPK), and technological pedagogical content knowledge (TPACK). Prior empirical research has proven this model valid and reliable to explain, examine, and develop teacher knowledge (Habibi et al., 2019; Özgür, 2020; Santika et al., 2021).

Prior researchers step further to investigate what knowledge affects teachers' technology decisions. Their findings 
are inconsistent. Some concur that TPACK predicts technology use in education. In a study reviewing 55 TPACK articles, Voogt et al. (2013) concluded that TPACK influenced teachers' decisions to teach with technology. Other quantitative studies agree that TPACK predicts technology use among language teachers in Iran (Raygan \& Moradkhani, 2020), in China (Hsu, 2016), and in United Arab Emirates (Khine et al., 2017). Nevertheless, as Joo et al. (2018) remind us, TPACK can indirectly affect teachers' intention to use technology via teacher and technology variables. According to Yang et al. (2019) and Hsu (2016), TPACK greatly impacts teachers' technology use through technological variables: perceived usefulness and ease of use. More researchers concur that TPACK influences teachers' self-efficacy and beliefs (Ching Sing Chai et al., 2013; Özgür, 2020). In short, the above studies remind us that TPACK has a direct or indirect impact on teachers' technology use. On the other hand, some researchers challenge TPACK to be the best predictor of technology integration. Khine et al. (2017) found moderate correlations between ICT scores and several constructs: CK, TK, TPK, and TPACK, refuting TPACK as the only determinant of ICT use. Their finding is supported by Zhou et al. (2017), who confirmed CK and PK as significant predictors of teachers' use of online homework. PK is reaffirmed as strongly influencing teachers' decisions regarding technology integration (Aslan \& Zhu, 2017; Saudelli \& Ciampa, 2016). However, in an e-platform acceptance study, TK outperforms PK and CK in such acceptance (Yang et al., 2019). Overall, teacher knowledge can influence technology use, but what knowledge best predicts such use is debatable.

Despite the above inconsistency, researchers show interest in how teachers perceive their knowledge for professional development and teacher education. Their studies show subtle differences regarding perceived knowledge profoundness. According to Kainat et al. (2021), secondary school teachers in Pakistan perceived a lack of TK. In contrast, Koh and Divaharan (2011) claimed that Netherlands teachers predominantly developed TK (and TPK) but lacked TCK and TPACK. This finding is further challenged by Dalal et al. (2017), who evaluated knowledge among secondary school teachers from developing nations. That study found TCK (and then TK) had the greatest gain in all TPACK domains. Despite regional differences, it is widely accepted that teachers are more confident in their non-technological knowledge (CK, PK, PCK) than technological knowledge (TK, TCK, TPK, TPACK) (Ching Sing Chai et al., 2013; Walker, 2017; Yang et al., 2019). Nevertheless, that does not mean all teachers are proficient in CK, PK, and PCK. Lee and Kim (2014) revealed that teachers had difficulties understanding PK, after examining TPACK surveys, lesson plans, and field notes. As Rohaan et al. (2012) recommend, teacher training should focus on "subject matter knowledge and pedagogical content knowledge" (p. 271). Although they did not say indirectly, their study implied a lack of CK and PCK among their participants.

In addition to teacher perception of their knowledge, researchers also focus on knowledge development. Raper (2018) surveyed 129 instructors to investigate teacher knowledge and their use of the Learning Management System (LMS). Teacher knowledge was related to three factors: general technology usage, teacher attitudes toward technology, and professional development. These three factors are supported by other investigations (Hsu, 2016; Raygan \& Moradkhani, 2020; Rohaan et al., 2012). Professional development is commonly considered the most effective strategy for TPACK development (Dalal et al., 2017; Koh et al., 2013; Saudelli \& Ciampa, 2016; Zhou et al., 2017).

Some researchers take further steps to study correlations between TPACK elements for knowledge development. The correlations, however, are debatable, supporting and opposing other studies. According to Pamuk et al. (2013), TPACK relationships are as follows: (a) second-layer knowledge bases (PCK, TCK, TPK) predict TPACK better than core knowledge bases (TK, PK, CK), (b) TCK, followed by TPK, is the strongest predictor of TPACK, (c) core knowledge bases indirectly influence TPACK, via second-layer knowledge, (d) core knowledge bases are correlated with their intersected knowledge (i.e., TK impacting TCK and TPK, CK impacting PCK and TCK, PK impacting PCK and TPK). These findings are fully supported by Santika et al. (2021) with their recent study examining structural relationships between TPACK components. Other researchers agreed on most yet opposed some of the above findings. Bostancioğlu and Handley (2018) and Habibi et al. (2019) repudiated TCK as the best predictor of TPACK, Ching Shing Chai et al. (2013) refuted the CK-PCK correlation, and Dong et al. (2015) denied the PCK-TPACK correlation. Dong et al. (2015) were further supported by Koh et al. (2013), whose study reiterated a missing path between PCK and TPACK. More importantly, Koh et al. (2013) argued that core knowledge bases TK and PK - directly impacted TPACK. The direct impact of core knowledge on TPACK continues to be proven. Bostancioğlu and Handley (2018) revealed that CK and TK directly affected TPACK, while Chai et al. (2012) claimed that CK and PK did. Khine et al. (2017) strengthened both findings, affirming that all core bases were significantly related to TPACK. Apparently, correlations between TPACK constructs are inconsistent. The controversy can hinder effective teacher education and knowledge development, urging more studies to clarify such relationships (Bostancıŏlu \& Handley, 2018; Lee \& Kim, 2014). 


\section{Methodology}

\subsection{Research Design}

This study used a phenomenological approach, which is deemed as the best research approach when "needing to describe the essence of a lived phenomenon" and "understanding the essence of the experience" (Creswell, 2019, p. 104). The researcher spotted a phenomenon - CFL teachers' technology use is closely related to their knowledge, and therefore, sought to understand such phenomenon through conducting this study. Simply put, this project investigates a phenomenon and how instructors perceive it, so a phenomenological study can best summarise its nature.

Besides, a quantitative research design was adopted. It helps standardise statistical data and address multiple issues shortly (Creswell, 2019). The questionnaire was checked for validity and reliability before data collection. Three specialists in tech based CFL teaching examined it. Their experience and expertise in Chinese instruction helped enrich the instrument to cover all questions probed and clarified. The researcher also had seven doctorate candidates proofread the instrument to eliminate content ambiguity and grammar errors. Apart from academic specialists, the researcher had two secondary school teachers review the instrument.

\subsection{Participants}

Table 1. Participants' Demographic Information

\begin{tabular}{|c|c|c|c|c|c|c|}
\hline Participant & Gender & Age range & $\begin{array}{l}\text { CFL } \\
\text { teaching } \\
\text { experience }\end{array}$ & $\begin{array}{l}\text { Number of } \\
\text { CFL teachers } \\
\text { in school }\end{array}$ & School type & $\begin{array}{l}\text { Chinese program } \\
\text { taught in school }\end{array}$ \\
\hline 1 & $\mathrm{~F}$ & $25-30$ & 3 years & 4 & State & $\mathrm{MC}$, \\
\hline 2 & $\mathrm{~F}$ & $30-35$ & 7 years & 5 & State & $\mathrm{AC}, \mathrm{MC}$ \\
\hline 3 & M & $60-70$ & 16 years & 3 & State & IC \\
\hline 4 & $\mathrm{~F}$ & $45-50$ & 9 years & 2 & Independent & $\mathrm{MC}$ \\
\hline 5 & $\mathrm{~F}$ & $30-35$ & 11 years & 3 & Independent & $\mathrm{MC}$ \\
\hline 6 & $\mathrm{~F}$ & $30-35$ & 7 years & 1 & Independent & $\mathrm{MC}$ \\
\hline 7 & $\mathrm{~F}$ & $20-25$ & 1 year & 3 & State & IC \\
\hline 8 & $\mathrm{M}$ & $30-35$ & 2 years & 3 & State & IC \\
\hline 9 & $\mathrm{~F}$ & $25-30$ & 3 years & 1 & Independent & $\mathrm{MC}$ \\
\hline 10 & M & $30-35$ & 7 years & 3 & State & $\mathrm{MC}$ \\
\hline 11 & $\mathrm{~F}$ & $30-35$ & 2.5 year & 1 & Independent & $\mathrm{MC}$ \\
\hline 12 & $\mathrm{~F}$ & $30-35$ & 7 years & 4 & Independent & $\mathrm{MC}$ \\
\hline 13 & $\mathrm{M}$ & $25-30$ & 1 year & 5 & State & $\mathrm{AC}, \mathrm{MC}$ \\
\hline 14 & $\mathrm{~F}$ & $45-50$ & 10 years & 5 & State & $\mathrm{AC}, \mathrm{MC}$ \\
\hline 15 & $\mathrm{~F}$ & $36-40$ & 6 years & 3 & State & $\mathrm{MC}$ \\
\hline 16 & M & $40-45$ & 7 years & 3 & State & $\mathrm{MC}$ \\
\hline 17 & $\mathrm{~F}$ & $31-35$ & 6 years & 2 & State & $\mathrm{MC}$ \\
\hline 18 & M & $41-45$ & 20 years & 3 & State & $\mathrm{MC}$ \\
\hline 19 & $\mathrm{~F}$ & $46-50$ & 5 years & 1 & State & $\mathrm{AC}$ \\
\hline 20 & $\mathrm{~F}$ & $36-40$ & 6 years & 4 & Independent & $\mathrm{MC}$ \\
\hline 21 & $\mathrm{~F}$ & $36-40$ & 8 years & 3 & State & $\mathrm{MC}$ \\
\hline 22 & $\mathrm{~F}$ & $36-40$ & 6 years & 3 & State & $\mathrm{MC}$ \\
\hline 23 & M & $51-55$ & 19 years & 2 & Independent & $\mathrm{MC}$ \\
\hline 24 & $\mathrm{~F}$ & $61-65$ & 20 years & 7 & State & $\mathrm{MC}$ \\
\hline 25 & $\mathrm{~F}$ & $26-30$ & 1 year & 7 & State & $\mathrm{MC}$ \\
\hline 26 & $\mathrm{~F}$ & $41-45$ & 3 years & 6 & State & $\mathrm{MC}$ \\
\hline 27 & $\mathrm{~F}$ & $41-45$ & 6 years & 7 & State & $\mathrm{MC}$ \\
\hline 28 & $\mathrm{~F}$ & $26-30$ & 3 years & 2 & Catholic & $\mathrm{MC}$ \\
\hline 29 & $\mathrm{M}$ & $46-50$ & 20 years & 8 & State & $\mathrm{MC}$ \\
\hline 30 & $\mathrm{~F}$ & $20-25$ & 1 year & 3 & State & $\mathrm{MC}$ \\
\hline 31 & $\mathrm{~F}$ & $36-40$ & 13 years & 4 & Independent & $\mathrm{MC}$ \\
\hline
\end{tabular}

(Note MC: Mainstream Chinese, AC: Accelerated Chinese, IC: Immersion Chinese) 
This study used a purposeful sample and recruited participants from secondary schools in Australia. The ideal number of participants for a phenomenological quantitative study is not specially addressed, but at least 25 respondents should be included (Creswell, 2019; Humble, 2020). A total of thirty-one participants who met the criteria participated in this study.

The criteria for participants in this study were that each participant (a) is an in-service teacher, (b) teaches in an Australian secondary school, and (c) teaches Chinese as a foreign language. " $90 \%$ of Chinese teachers in Australia are native speakers, most by far coming from the Chinese mainland, but there are also some from Taiwan and South-East Asia" (Sturak \& Naughten, 2010, p. 12). They came from different Chinese programmes, including Mainstream Chinese, Immersion Chinese, and Accelerated Chinese. The first program uses English as the instruction language, while the latter two use Chinese to teach other subjects (e.g., math, science). Table 1 displays the demographic information of the participants.

\subsection{Data Collection and Analysis Procedures}

This study collected data from July 2019 to November 2020, when secondary school participants endorsed participating in the study. There were five stages of data collection: finding participants, contacting participants via email, seeking participation consent, discussing details of conducting the questionnaire, and collecting the questionnaire. With specific criteria kept in mind, the researcher contacted in-service CFL teachers via emails, disseminating Participant Information Sheet, Participant Consent Form, and other research protocol files. Delivering these files was to inform instructors of the study and obtain their participation approval. At last, a total of 31 respondents were recruited for the study.

After the data collection, they were analysed in Statistical Package for Social Sciences (SPSS), a statistic analysing tool. The Likert-scale questionnaires for this study contain five points: Strongly Agree, Agree, Neither Agree nor Disagree, Disagree, and Strongly Disagree. The five-point questionnaires were adapted from published papers, and the authors have instructed how to score and analyse them. "Each item response is scored with a value of 1 assigned to Strongly Disagree, all the way to 5 for Strongly Agree. For each construct, the participant's responses are averaged" (Schmidt et al., 2009a, p. 1). For example, the six questions under the Content Knowledge (CK) section in the Teacher Knowledge and Technology Use Questionnaire are averaged to create a CK Score that indicates teachers' CK proficiency. Following the instruction, the researcher created SPSS files by converting the Likert items into numeral data. Figures, such as mean, standard deviation, and medium, indicate participants' teacher knowledge mastery. The following analysis involved Spearman's Rank-Order correlation (Spearman's rho) in determining relationships between teacher knowledge. Upon completing data analysis, the results and findings are presented in the following section.

\section{Results and Findings}

The Teacher Knowledge and Technology Use Questionnaire runs a four-step analysis: reliability test, percentage of responses, descriptive statistics, and correlation construction. This study employs Spearman's Rank-Order correlation to deal with non-normally distributed Likert data. Correlation matrices are constructed to visualise relationships between variables.

\subsection{Reliability Test}

All questionnaires should be internally consistent with reliable research data (Dornyei \& Taguchi, 2010). The reliability statistics of this questionnaire is run by SPSS and shown in Table 2. The table reports a Cronbach's Alpha and a Standardised Alpha. Both values are similar and reportable in studies.

Table 2. Reliability Statistics of the Questionnaire

\begin{tabular}{lcc}
\hline Cronbach's Alpha & $\begin{array}{c}\text { Cronbach's Alpha Based on Standardised } \\
\text { Items }\end{array}$ & N of Items \\
\hline .925 & .910 & 36 \\
\hline
\end{tabular}

The researcher used Cronbach's alpha to test the reliability of the questionnaire items. Cronbach's alpha is a measure widely used to examine the strength of internal consistency of test items - how close a set of items are related as a group (Wilson, 2013). Based on the rule of thumb for interpreting Cronbach's alpha for Likert items, the Likert items have excellent internal consistency when the alpha is greater than .90. The Cronbach's alpha of this questionnaire is .925 , indicating that it is highly reliable. 
Table 3. Percentage of Participants' Responses to the Questionnaire Items

\begin{tabular}{|c|c|c|c|c|c|}
\hline Questionnaire items & $\begin{array}{l}\text { SA } \\
(\%)\end{array}$ & $\begin{array}{l}\text { A } \\
(\%)\end{array}$ & $\begin{array}{l}\text { NAND } \\
(\%)\end{array}$ & $\begin{array}{l}\mathrm{D} \\
(\%)\end{array}$ & $\begin{array}{l}\mathrm{SD} \\
(\%)\end{array}$ \\
\hline \multicolumn{6}{|l|}{ Technology Knowledge (TK) } \\
\hline 1. I know how to solve my own technical problems. & 12.9 & 64.52 & 19.35 & 3.23 & 0 \\
\hline 2. I know how to use web 2.0 technologies (e.g., blogs, wikis). & 41.94 & 45.26 & 9.68 & 3.23 & 0 \\
\hline 3. I know about a lot of different Chinese learning technologies. & 9.68 & 45.26 & 35.48 & 9.68 & 0 \\
\hline 4. I frequently play around with Chinese learning technologies. & 19.35 & 45.26 & 25.81 & 9.68 & 0 \\
\hline 5. I can keep up with new Chinese learning technologies. & 19.35 & 48.39 & 19.35 & 12.9 & 0 \\
\hline \multicolumn{6}{|l|}{ Content Knowledge (CK) } \\
\hline 6. I can use Chinese language accurately. & 74.19 & 25.81 & 0 & 0 & 0 \\
\hline 7. I can describe phonological features (pinyin) of Chinese language. & 90.32 & 9.68 & 0 & 0 & 0 \\
\hline 8. I can describe semantic meanings of Chinese language. & 64.52 & 32.26 & 3.23 & 0 & 0 \\
\hline 9. I have sufficient knowledge of Chinese language skills (e.g., writing). & 80.65 & 19.35 & 0 & 0 & 0 \\
\hline 10. I am familiar with the cultures of Chinese communities. & 80.65 & 19.35 & 0 & 0 & 0 \\
\hline \multicolumn{6}{|l|}{ Pedagogical Knowledge (PK) } \\
\hline $\begin{array}{l}\text { 11. I can adapt my teaching in class, based upon what students currently understand } \\
\text { or do not understand. }\end{array}$ & 54.84 & 41.94 & 3.23 & 0 & 0 \\
\hline 12. I can adapt my teaching style to individual learners and different cohorts. & 51.61 & 41.94 & 6.45 & 0 & 0 \\
\hline 13. I can assess students' learning in multiple ways. & 61.29 & 29.03 & 9.68 & 0 & 0 \\
\hline 14. I can use a wide range of teaching approaches in a classroom setting. & 54.84 & 35.48 & 9.68 & 0 & 0 \\
\hline 15. I am familiar with common student understandings and misconceptions. & 54.84 & 38.71 & 6.45 & 0 & 0 \\
\hline \multicolumn{6}{|l|}{ Pedagogical Content Knowledge (PCK) } \\
\hline 16. I can give appropriate feedback to my students. & 64.52 & 35.48 & 0 & 0 & 0 \\
\hline 17. I can select authentic Chinese language resources to suit students' needs. & 58.06 & 38.71 & 3.23 & 0 & 0 \\
\hline $\begin{array}{l}\text { 18. I can identify linguistic problems experienced by students (e.g., grammatical } \\
\text { problems, stroke order). }\end{array}$ & 70.97 & 29.03 & 0 & 0 & 0 \\
\hline 19. I can choose an appropriate approach to teaching Chinese language. & 58.06 & 35.48 & 6.45 & 0 & 0 \\
\hline $\begin{array}{l}\text { 20. I can design Chinese teaching activities based on the requirements of the } \\
\text { curriculum. }\end{array}$ & 67.74 & 29.03 & 3.23 & 0 & 0 \\
\hline \multicolumn{6}{|l|}{ Technological Content Knowledge (TCK) } \\
\hline 21. I know about technologies that I can use to teach Chinese language. & 25.81 & 67.74 & 6.45 & 0 & 0 \\
\hline $\begin{array}{l}\text { 22. I know about the technologies that I can use to teach different Chinese language } \\
\text { skills (e.g., listening, speaking). }\end{array}$ & 25.81 & 61.29 & 9.68 & 3.23 & 0 \\
\hline 23. I know about the technologies that I can use to teach Chinese characters. & 19.35 & 51.61 & 22.58 & 6.45 & 0 \\
\hline $\begin{array}{l}\text { 24. I know about the technologies that I can use to teach semantic meanings of } \\
\text { Chinese language. }\end{array}$ & 19.35 & 41.94 & 25.81 & 12.9 & 0 \\
\hline $\begin{array}{l}\text { 25. I know about the technologies that I can use to teach Chinese cultural elements. } \\
\text { Technological Pedagogical Knowledge (TPK) }\end{array}$ & 19.35 & 54.84 & 16.13 & 9.68 & 0 \\
\hline 26. I can choose technologies that enhance teaching approaches. & 29.03 & 58.06 & 12.9 & 0 & 0 \\
\hline 27. I can choose technologies that enhance students' learning. & 29.03 & 61.29 & 9.68 & 0 & 0 \\
\hline 28. I can choose technologies that enhance the content for a lesson. & 35.48 & 48.39 & 16.13 & 0 & 0 \\
\hline 29. I can think critically about how to use technology in my classroom. & 41.94 & 45.26 & 12.9 & 0 & 0 \\
\hline \multicolumn{5}{|l|}{ Technology Pedagogy and Content Knowledge (TPACK) } & 0 \\
\hline $\begin{array}{l}\text { 31. I can teach Chinese language in ways that appropriately combine linguistic } \\
\text { aspects, technologies, and teaching approaches. }\end{array}$ & 25.81 & 61.29 & 12.9 & 0 & 0 \\
\hline $\begin{array}{l}\text { 32. I can select appropriate Chinese learning technologies to enhance what I teach, } \\
\text { how I teach, and what students learn. }\end{array}$ & 32.26 & 45.26 & 22.58 & 0 & 0 \\
\hline \multicolumn{6}{|l|}{ Technology Use (TU) } \\
\hline 33. I mainly use technologies as a pedagogical delivery tool to deliver content. & 3.23 & 9.68 & 16.13 & 48.39 & 22.58 \\
\hline 34. I mainly use technologies as a reward to entertain students. & 9.68 & 16.13 & 32.26 & 25.81 & 16.13 \\
\hline 35. I mainly use technologies as a curriculum tool to improve teaching efficiency. & 32.26 & 45.26 & 12.90 & 6.45 & 3.23 \\
\hline 36. I mainly use technologies as a provider of new learning environments. & 16.13 & 61.29 & 6.45 & 12.90 & 3.23 \\
\hline
\end{tabular}


In addition to a high Cronbach's alpha, this questionnaire is reliable, adapted from two published questionnaires with close internal consistency. The Cronbach's alpha of the first adapted questionnaire is from .75 to .92 for the seven TPACK subscales (Schmidt et al., 2009b), and the alpha ranges from .82 to .89 for the second questionnaire (Bostancioğlu \& Handley, 2018).

\subsection{Percentage of Responses}

All participants $(\mathrm{N}=31)$ show their perceptions of each questionnaire item by ticking one of the corresponding points. Those five points are Strongly Agree (SA), Agree (A), Neither Agree nor Disagree (NAND), Disagree (D), and Strongly Disagree (SD). Table 3 summarises participants' responses to each questionnaire item in percentage.

Table 3 presents that all questionnaire items are completed. No item is left blank. In addition, participants feel optimistic about their knowledge, as most responses concentrate on "Strongly Agree" or "Agree". Besides, participants perceive they have profound CK, PK, and PCK because they "Strongly Agree" with those three domains more than the sum of the other four options. At the same time, they are less favourable to TK and TCK because they exclusively "Disagree" with those two domains. Lastly, responses to the TU construct are diverse, covering all five Likert scales. The variety suggests that participants incorporate technology distinctly.

\subsection{Descriptive Statistics}

Each knowledge attribute has been analysed. The participant's responses to each knowledge domain are averaged to a two-digit score. The average score indicates the strength and weaknesses of participants' knowledge. Instructed by the questionnaire designers (Schmidt et al., 2009b), the researcher further analyses those scores. For example, the TK Score is calculated by averaging the five items under TK to examine participants' technological knowledge. Table 4 illustrates the average scores in descending order.

Table 4. Average Score by Each Knowledge Attribute

\begin{tabular}{ll}
\hline Attribute & Average Score \\
\hline Content Knowledge (CK) & 4.77 \\
Pedagogical Content Knowledge (PCK) & 4.61 \\
Pedagogical Knowledge (PK) & 4.48 \\
Overall Knowledge Score* (OK Score) & 4.28 \\
Technological Pedagogical Knowledge (TPK) & 4.19 \\
Technological Pedagogical and Content Knowledge (TPACK) & 4.11 \\
Technological Content Knowledge (TCK) & 3.93 \\
Technological Knowledge (TK) & 3.83 \\
\hline
\end{tabular}

The Overall Knowledge Score*, abbreviated as OK Score, was the mean of all participants' overall knowledge (items 1-32).

The OK Score (4.28) represents participants' average mastery of teacher knowledge. Three scores (TK Score, PK Score, and PCK Score) are higher than OK Score, suggesting participants perceived profound in CK, PK, and PCK. By comparison, four scores (TK, TCK, TPK, TPACK) are lower than the OK Score. The result indicates that participants reported less profound TK, TCK, TPK, and TPACK. These four constructs are technology-related, postulating that participants lacked technology-related knowledge. In other words, the respondents are confident in non-technology knowledge (CK, PK, and PCK) and reserved in technology-related knowledge (TK, TCK, TPK, and TPACK).

The higher a score ranks, the more knowledgeable a respondent perceives. The highest score in Table 4 is CK Score (4.77), implying that participants perceive themselves as most knowledgeable in teaching content. The second and the third-highest scores are PCK Score (4.61) and PK Score (4.48). These ranks indicate participants' sound pedagogies. The result agrees with Table 3, where most participants "Strongly Agree" with CK, PK, and PCK items. More importantly, the top three scores (CK, PK, and PCK) suggest that the participants obtain critical knowledge proposed by Shulman (1986). Shulman proposes that PK and CK are teacher knowledge bases, and a qualified teacher combines PK and CK skillfully in their teaching.

The lowest score is TK Score (3.83), indicating that participants' technological knowledge may be the weakest among TPACK constructs. The second, the third, and the fourth-lowest scores are TCK $(3.93)$, TPACK $(4,11)$, and TPK (4.39). These relatively lower scores indicate a lack of participants' technological knowledge. 
Technology-based knowledge awaits to be improved.

\subsection{Correlation Construction}

Correlation analysis is conducted via SPSS to explore the relationships between TPACK domains and technology use. This study employs Spearman's Rank-Order correlation (Spearman's rho), a widely used nonparametric test, to deal with the non-normally distributed data. It "measures the strength and direction of association between two ranked variables" and describes a monotonic relationship in which "one variable increases, the other either increases or decreases" (Humble, 2020, p. 64). Spearman's rho greater than 0 indicates a positive relationship between variables, and that less than 0 is a negative correlation (Prion \& Haerling, 2014). Table 5 provides a detailed grading table of Spearman's rho.

Table 5. Grading Table of Spearman's rho ( $\rho$ ) (Prion \& Haerling, 2014)

\begin{tabular}{ll}
\hline Grading Standards & Correlation Degree \\
\hline$\rho=0$ & no correlation \\
$0<|\rho| \leq 0.19$ & very week \\
$0.20 \leq|\rho| \leq 0.39$ & weak \\
$0.40 \leq|\rho| \leq 0.59$ & moderate \\
$0.60 \leq|\rho| \leq 0.79$ & strong \\
$0.80 \leq|\rho| \leq 1.00$ & very strong \\
1.00 & Monotonic correlation \\
\hline
\end{tabular}

The researcher averages each participant' responses to every knowledge component. For instance, Participant A's responses to items under CK are averaged to produce Participant A's CK Score. Such average scores present each participant's mastery of TPACK knowledge. The participants' average scores are imported into SPSS to calculate Spearman's rho to uncover the relationships of TPACK attributes and technology use. This statistical test can measure the strength and direction of association between two attributes. Table 6 shows the result of Spearman's rho.

Table 6. Spearman's rho $(\rho)$ between Average Scores of the Questionnaire

\begin{tabular}{lllllllllll}
\hline & $\begin{array}{l}\text { TK } \\
\text { Score }\end{array}$ & $\begin{array}{l}\text { CK } \\
\text { Score }\end{array}$ & $\begin{array}{l}\text { PK } \\
\text { Score }\end{array}$ & $\begin{array}{l}\text { PCK } \\
\text { Score }\end{array}$ & $\begin{array}{l}\text { TCK } \\
\text { Score }\end{array}$ & $\begin{array}{l}\text { TPK } \\
\text { Score }\end{array}$ & $\begin{array}{l}\text { TPACK } \\
\text { Score }\end{array}$ & $\begin{array}{l}\text { OK } \\
\text { Score }\end{array}$ & TU1 & TU2 \\
\hline TK Score & 1 & & & & & & & & & \\
CK Score & .231 & 1 & & & & & & & & \\
PK Score & .270 & .144 & 1 & & & & & & & \\
PCK Score & .185 & $.544^{* *}$ & $.587^{* *}$ & 1 & & & & & & \\
TCK Score & $.616^{* *}$ & .165 & $.515^{* *}$ & .344 & 1 & & & & & \\
TPK Score & $.459^{* *}$ & .164 & $.474^{* *}$ & $.478^{* *}$ & $.751^{* *}$ & 1 & & & & \\
TPACK Score & $.476^{*}$ & .284 & $.444^{*}$ & $.644^{* *}$ & $.636^{* *}$ & $.836^{* *}$ & 1 & & & \\
OK Score & $.585^{* *}$ & $.444^{*}$ & $.698^{* *}$ & $.691^{* *}$ & $.848^{* *}$ & $.850^{* *}$ & $.852^{* *}$ & 1 & & \\
TU1 & $.489^{*}$ & .034 & .207 & .157 & .099 & .131 & .034 & .212 & 1 & \\
TU2 & $.472^{*}$ & .194 & .213 & .192 & .184 & .118 & .210 & .288 & $.468^{* *}$ & 1 \\
**. Correlation is significant at the 0.01 level (2-tailed). & & & & & & \\
*. Correlation is significant at the 0.05 level (2-tailed). & & & & & & \\
\hline
\end{tabular}

All figures in Table 6 are greater than zero, suggesting that all knowledge constructs and technology use correlate. A positive Spearman correlation coefficient represents an increasing monotonic trend between two variables (Prion \& Haerling, 2014). That is, when one knowledge construct increases, the other construct may increase as well.

Firstly, TU is divided into TU1 and TU2 to represent two levels of technology use. TU1 is the elementary level use of technology, which uses technology for non-instructional purposes (item 34) or a direct tool substitute (item 33). In stark contrast, TU2 is a higher-level use of technology, which uses technology to transform teaching tasks (items 35 , 36 ). TK is the only knowledge to be significantly correlated with TU. It is moderately correlated with TU1 ( $\rho=0.489$, $\mathrm{n}=31, \mathrm{p}<0.05)$ and TU2 $(\rho=0.472, \mathrm{n}=31, \mathrm{p}<0.05)$. The result implies that a TK increase can lead to a TU increase. Other knowledge constructs have no significant correlations with TU1 and TU2. Likewise, neither TU1 nor TU2 is significantly correlated with the OK Score - the mean of all participants' overall knowledge. That is, teacher knowledge may not directly affect technology use. 
Besides, all knowledge figures are significantly correlated with the OK Score. The result indicates that every knowledge domain predicts a teacher's knowledge. TPACK is most strongly correlated with the OK Score ( $\rho=0.852$, $\mathrm{n}=31, \mathrm{p}<0.01$ ), postulating it as the strongest predictor of teacher knowledge. Meanwhile, PK-OQ correlation $(\rho=0.698, n=31, p<0.01)$ is stronger than CK- and TK-OQ, suggesting PK as the most reliable knowledge base to predict a teacher's knowledge. Figure 1 shows all significant correlations of various strengths.

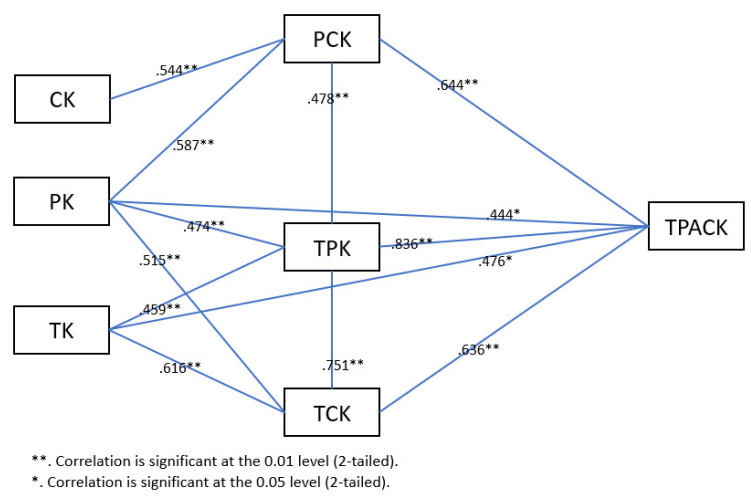

Figure 1. Significant Correlations between TPACK Domains

Strong positive correlations $(0.6<\rho<0.79)$ are observed between multiple constructs. A strong positive correlation suggests that one variable increases, the other also increases (Prion \& Haerling, 2014). Strong correlations are visualised in Figure 2.

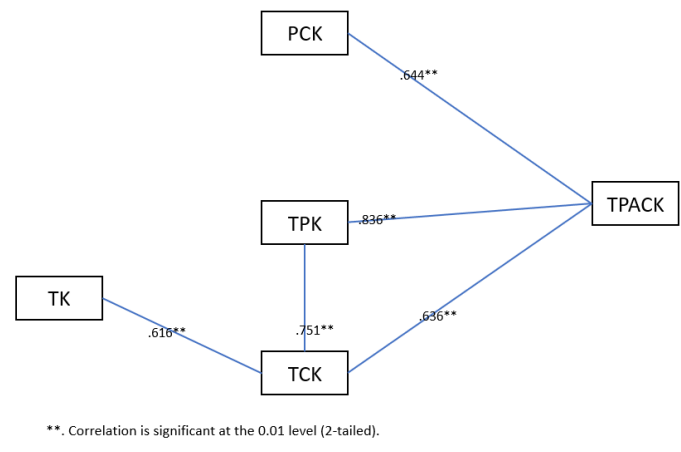

Figure 2. Strong Positive Correlations between TPACK Domains

TK is strongly correlated with TCK $(\rho=0.616, n=31, p<0.01)$. When teachers increase TK, their TCK is predicted to increase as well. TCK is strongly correlated with TPK $(\rho=0.751, n=31, p<0.01)$ and TPACK $(\rho=0.636, n=31$, $\mathrm{p}<0.01$ ), which suggests that an increase of TCK is associated with TPK and TPACK improvement. TK increase links with TCK enhancement, which in turn correlates with TPK and TPACK. In other words, TK may positively influence TCK, TPK, and TPACK.

Likewise, TPK is strongly correlated with TCK $(\rho=0.751, n=31, p<0.01)$ and TPACK $(\rho=0.836, n=31, p<0.01)$. The strong TCK-TPK correlation indicates a close TCK-TPK relationship. Meanwhile, only the TPK-TPACK correlation is defined as "very strong" among all established correlations. This strongest relationship implies that TPK is the best predictor of TPACK.

Finally, TPACK is strongly correlated with PCK $(\rho=0.644, n=31, p<0.01)$, TCK $(\rho=0.636, n=31, p<0.01)$ and TPK $(\rho=0.836, \mathrm{n}=31, \mathrm{p}<0.01)$. The result uncovers a close relationship among these knowledge domains. That is, when PCK, TCK, or TPK enhances, TPACK increases as well. Among them, TPK is the most intimately associated with TPACK. Overall, TK is expected to be vital in intersected knowledge (TCK, TPK and TPACK). Teachers must enhance their TK if they aspire to develop TPACK. 
Moderate positive correlations $(0.4<\rho<0.59)$ are visualised in Figure 3.

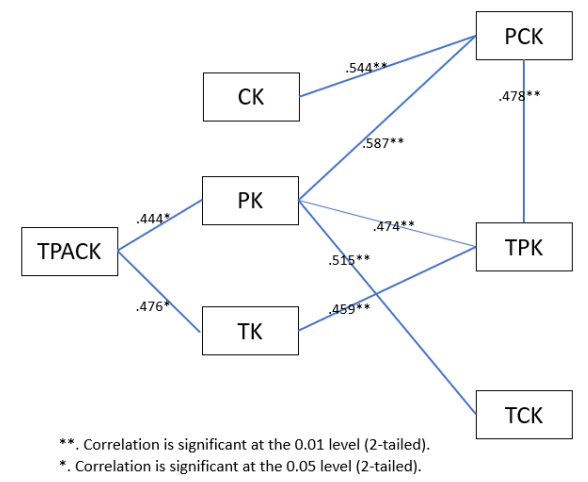

Figure 3. Moderate Positive Correlations between TPACK Domains

TK is observed to moderately correlated with TPK $(\rho=0.459, n=31, p<0.01)$, and TPACK $(\rho=0.476, n=31, p<0.05)$. The TK-TPACK correlation is slightly stronger than the TK- TPK correlation, suggesting that TK is more closely associated with TPACK than TPK. Likewise, CK is moderately linked with only PCK $(\rho=0.544, n=31, p<0.01)$. This result infers that PCK may be the only significantly co-boosted knowledge if teachers boost CK. The CK-PCK relationship explains why teachers might have low TPACK Score, even though their CK Score is high.

Besides, PK is moderately correlated with multiple knowledge aspects (i.e., PCK, TCK, TPK, and TPACK). The PK-PCK correlation $(\rho=0.587, n=31, p<0.01)$ is stronger than that of PK-TCK $(\rho=0.515, n=31, p<0.01)$, PK-TPK $(\rho=0.474, n=31, p<0.01)$, and PK-TPACK $(\rho=0.444, n=31, p<0.05)$. According to these findings, PK helps develop overall knowledge, especially PCK. Similarly, PCK is moderately correlated with multiple knowledge. It links with TPK $(\rho=0.478, \mathrm{n}=31, \mathrm{p}<0.01)$ and its knowledge bases: CK $(\rho=0.544, \mathrm{n}=31, \mathrm{p}<0.01)$ and PK $(\rho=0.587, \mathrm{n}=31$, $p<0.01)$. Likewise, TPK is moderately correlated with its two knowledge bases: TK $(\rho=0.459, n=31, p<0.01)$ and PK $(\rho=0.474, \mathrm{n}=31, \mathrm{p}<0.01)$. Moreover, TPACK is also found correlated with its knowledge bases: TK $(\rho=0.476, \mathrm{n}=31$, $\mathrm{p}<0.05)$ and PK $(\rho=0.444, n=31, p<0.05)$. It implies that an increase in knowledge bases (except $C K)$ may improve TPACK.

According to the above, intersected knowledge is correlated with its knowledge bases, for example, PCK to PK and CK, TPK to TK and PK. Moreover, intersected knowledge may be related, such as PCK to TPK. Meanwhile, a moderate correlation is found between TCK and PK $(\rho=0.515, n=31, p<0.01)$. The result suggests that TCK development may increase PK - an unrelated knowledge base.

Weak positive correlations $(0.2<\rho<0.39)$ are also observed in Figure 1. An increase in one knowledge construct does not guarantee an increase in another. Figure 4 visualises weakly correlated constructs.

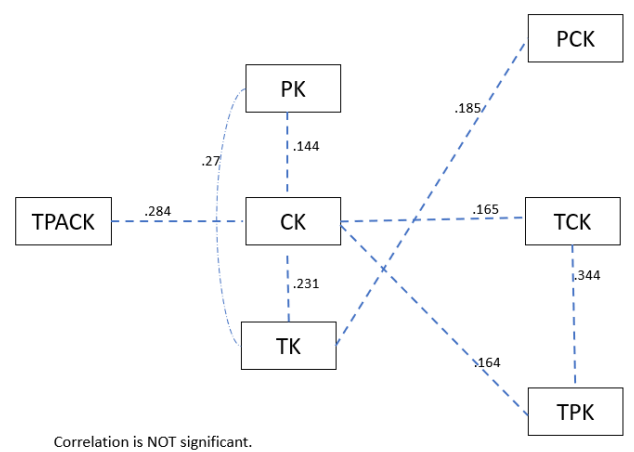

Figure 4. Weak Positive Correlations between TPACK Domains

TK is weakly correlated with CK, PK, and PCK. It makes sense as TK is distinct from CK, PK, and PCK, thus possibly irrelevant to these three knowledge attributes. More significantly, CK is weakly correlated with multiple domains (TK, PK, TCK, TPK, and TPACK). In other words, increasing CK does not guarantee improvement in the 
above knowledge. If teachers aspire to develop their knowledge effectively, CK should not be a priority. Besides, PCK is unrelated to TCK, despite sharing the same knowledge base - CK.

\section{Discussion and Conclusion}

\subsection{The Influence of Teacher Knowledge on Technology Use}

Teacher knowledge is perceived to influence technology consideration among CFL teachers. An increase in teacher knowledge boosts technology-integrated practice and the capability to deliver such practice. Nonetheless, not all knowledge is significantly correlated with technology use. This study supports Joo et al. (2018), who discovered that "TPACK did not directly affect their intention to use technology" (p. 48).

Technological knowledge (TK) is the only construct that predicts technology use in this study. That is, the overall teacher knowledge or other constructs are not statistically correlated with technology use. It evidences that TK is the strong predictor of technology implementation and integration (Banas \& York, 2014). It is also supported by Ifinedo et al. (2020), who concurred on a close relationship between TK and technology integration among teachers. Despite its significance, it is the least profound and the missing knowledge among participants. Hence, lacking TK is a barrier to technology use in CFL teaching. This finding suggests that a lack of TK is not immune to CFL teaching, the same as other subject areas in previous studies (Kainat et al., 2021).

Besides, there is controversy on how other knowledge constructs affect technology use in CFL instruction. Take CK and PK as an example. They are not found quantitatively correlated with technology use. Nonetheless, prior studies suggested that they could promote technology use (Zhou et al., 2017), while others raised an entirely contrasting point (Aslan \& Zhu, 2017; Saudelli \& Ciampa, 2016).

\subsection{Teacher Perception of Teacher Knowledge}

Technology-related knowledge (TK, TCK, TPK, TPACK) is less profound than non-technology constructs (CK, PK, PCK). This study aligns with recent studies that teachers are more confident in their non-technology knowledge than technological knowledge (Ching Sing Chai et al., 2013; Walker, 2017; Yang et al., 2019). For instance, Walker (2017) confirmed that teachers were more confident in CK and PK than technology-related knowledge, after surveying over 300 schoolteachers about their TPACK. Nonetheless, the excellence of CK, PK, and PCK is not inadequate for teachers in modern times. "A new set of teaching competencies is required for helping learners to take advantage of technology as well as to plan and work within new types of language curricula" (Heift \& Chapelle, 2012, p. 565).

Besides, CFL staff may lack TK and PK. TK shortage is a barrier to inactive, faltering, and restrained classroom technology use. Such shortage results from a lack of time and professional development to explore technologies (Zhou et al., 2017). On the other hand, PK is missing because CFL is distinct from teaching Chinese as a first language, and students differ in their Chinese proficiency and language backgrounds (Koh \& Divaharan, 2011).

Furthermore, PK is perceived to be the most significant knowledge. CFL teachers highlight the understanding of second language acquisition, student needs, and the Australian Curriculum, which can be challenging for CFL instructors. For instance, "insufficient understanding about students" is one of the challenges CFL teachers face in Australian schools (Chen, 2015, p. 937). In addition to PK, TPACK is deemed the most significant knowledge (Walker, 2017). It is also the ideal knowledge teachers can acquire to support digitalised education (Raper, 2018). CFL teaching, like other professions, "is changing as the result of the pervasive use of technology and therefore teachers need to be able to use and develop technology-based learning materials most conducive to language learning" (Heift \& Chapelle, 2012, p. 565).

\subsection{Teacher Perception of Teacher Knowledge Development}

Knowledge development is important for technology use, as it is the key to the transition from low to high level technology use (Raygan \& Moradkhani, 2020). This study provides straightforward solutions for knowledge development through unpacking relationships between TPACK elements.

The findings shed light on what to focus on to cultivate knowledge. TPK is the strongest predictor of TPACK (Bostancioğlu \& Handley, 2018; Habibi et al., 2019). As a result, a PD should develop TPK to increase teachers' TPACK. This finding is further supported by Schmidt et al. (2009a), who confirmed a significant correlation between TPK and TPACK. At the same time, this study opposes previous literature that suggests TCK as the best predictor of TPACK (Ching Shing Chai et al., 2013; Koh et al., 2013; Pamuk et al., 2013). Furthermore, this study underlines that TK is the most influential knowledge base for TPACK development. That is, TK should be 
spotlighted in the TPACK pursuit. The finding contradicts studies that reveal indirect relationships between TK and TPACK (Chai et al., 2012; Ching Shing Chai et al., 2013; Pamuk et al., 2013). Nonetheless, it is further supported by Koh et al. (2013), who confirmed the direct impact of TK on TPACK.

There are unexpected findings related to knowledge bases and intersected knowledge. First, knowledge bases may not significantly influence each other nor TPACK development. Understandably, teachers may not expect a CK or PK increase to improve their TK and vice versa (Ching Shing Chai et al., 2013). Also, CK, sufficiently possessed by most teachers, is the least influential TPACK impetus (Koh et al., 2013). Therefore, it is unwise to aim at a CK increase if TPACK development is the objective. A focus on PK, if not TK, enjoys better odds to enhance TPACK (Khine et al., 2017; Koh et al., 2013). Second, intersected knowledge can be correlated with its knowledge base but in different degrees. For example, TPK is significantly associated with its knowledge bases: PK and TK. The PK-TPK correlation is stronger than the TK-TPK one, implying a PK increase is more likely to cause a TPK improvement. The finding is supported by previous investigations that uncover significant relationships between knowledge bases and their intersected knowledge (Dong et al., 2015; Pamuk et al., 2013). Correlation strength deserves our attention while developing intersected knowledge. Focusing on a highly correlated knowledge base can only improve such intersected knowledge. Third, intersected knowledge may correlate with a non-intersected knowledge base. It is unwise to neglect that finding. TCK is significantly correlated with PK, a non-intersected base of TCK. That is, a PK increase is surprisingly likely to bring a TCK change. This finding opposes prior studies that generally recognise TCK to be affected by TK and CK (Ching Shing Chai et al., 2013; Koh et al., 2013; Pamuk et al., 2013).

To summarise, the significant correlations between TPACK domains are as follows: (a) intersected knowledge (PCK, TPK, TCK) are more predictive of TPACK than core knowledge (CK, PK, TK), (b) TPK is the strongest predictor of TPACK, (c) core knowledge bases (except CK) are significantly correlated with TPACK, (d) TK is the strongest TPACK predictor among core knowledge, and (f) core knowledge bases are correlated with relevant intersected knowledge. Nonetheless, the last finding has exceptions. CK is only related to PCK, but not with TCK. PK is correlated with PCK, TPK, and surprisingly, TCK as well.

Teachers perceive themselves as more profound in non-technology knowledge (CK, PK, PCK) than technology-related knowledge (TK, TCK, TPK, TPACK). CK is the most sufficient but the least influential knowledge to develop TPACK. It is perceived as the most sufficient, but it may only affect TPACK via PCK. By contrast, the other two bases (PK, TK) can directly affect TPACK. TK is observed to be the least profound but the most powerful TPACK predictor among core bases. Therefore, it should be prioritised to develop TPACK. Lastly, while TPK is the best predictor of TPACK, it is not sufficient knowledge for CFL participants. As a result, it should be prioritised in the TPACK development.

\section{References}

Aslan, A., \& Zhu, C. (2017). Investigating variables predicting Turkish pre-service teachers' integration of ICT into teaching practices. British Journal of Educational Technology, 48(2), 552-570. https://doi.org/10.1111/bjet.12437

Banas, J. R., \& York, C. S. (2014). Authentic learning exercises as a means to influence preservice teachers' technology integration self-efficacy and intentions to integrate technology. Australasian Journal of Educational Technology, 30(6), 728-746. https://doi.org/10.14742/ajet.362

Bostancıŏlu, A., \& Handley, Z. (2018). Developing and validating a questionnaire for evaluating the EFL 'Total PACKage': Technological Pedagogical Content Knowledge (TPACK) for English as a Foreign Language (EFL). Computer Assisted Language Learning, 31, 572-598. https://doi.org/10.1080/09588221.2017.1422524

Chai, C. S., Chin, C. K., Koh, J. H. L., \& Tan, C. L. (2013). Exploring Singaporean Chinese Language Teachers' Technological Pedagogical Content Knowledge and its Relationship to the Teachers' Pedagogical Beliefs. The Asia-Pacific Education Researcher, 22(4), 657-666. https://doi.org/10.1007/s40299-013-0071-3

Chai, C. S., Koh, J. H. L., Ho, H. N. J., \& Tsai, C.-C. (2012). Examining preservice teachers' perceived knowledge of TPACK and cyberwellness through structural equation modeling. Australasian Journal of Educational Technology, 28(6), 1000-1019. https://doi.org/10.14742/ajet.807

Chai, C. S., Ng, E. M. W., Li, W., Hong, H.-Y., \& Koh, J. H. L. (2013). Validating and modelling technological pedagogical content knowledge framework among Asian preservice teachers. Australasian Journal of Educational Technology, 29(1), 41-53. https://doi.org/10.14742/ajet.174 
Chen, Z. (2015). Challenges of Teaching Chinese in Australian Schools: Lesson from Beginning Teacher-researchers. Journal of Language Teaching and Research, 6(5), 933-942. https://doi.org/10.17507/jltr.0605.04

Creswell, J. W. (2019). Educational research : planning, conducting, and evaluating quantitative and qualitative research (6th ed.). Pearson.

Dalal, M., Archambault, L., \& Shelton, C. (2017). Professional Development for International Teachers: Examining TPACK and Technology Integration Decision Making. Journal of Research on Technology in Education, 49, 117-133. https://doi.org/10.1080/15391523.2017.1314780

Dong, Y., Chai, C. S., Sang, G.-Y., Koh, J. H. L., \& Tsai, C.-C. (2015). Exploring the Profiles and Interplays of Pre-service and In-service Teachers' Technological Pedagogical Content Knowledge (TPACK) in China. Educational Technology \& Society, 18(1), 158-169.

Dornyei, Z., \& Taguchi, T. (2010). Questionnaires in second language research: Construction, administration, and processing. Routledge.

Ertmer, P. A., Ottenbreit-Leftwich, A. T., Sadik, O., Sendurur, E., \& Sendurur, P. (2012). Teacher beliefs and technology integration practices: A critical relationship. Computers \& Education, 59(2), 423-435. https://doi.org/10.1016/j.compedu.2012.02.001

Habibi, A., Yusop, F. D., \& Razak, R. A. (2019). The role of TPACK in affecting pre-service language teachers' ICT integration during teaching practices: Indonesian context. Education and Information Technologies, 25(3), 1929-1949. https://doi.org/10.1007/s10639-019-10040-2

Heift, T., \& Chapelle, C. A. (2012). Language Learning through technology. In S. M. Gass \& A. Mackey (Eds.), The Routledge handbook of second language acquisition (pp. 555-570). Taylor \& Francis Group.

Hsu, L. (2016). Examining EFL teachers' technological pedagogical content knowledge and the adoption of mobile-assisted language learning: a partial least square approach. Computer Assisted Language Learning, 29(8), 1287-1297. https://doi.org/10.1080/09588221.2016.1278024

Humble, S. (2020). Quantitative analysis of questionnaires: Techniques to explore structures and relationships. RoutledgeTaylor \& Franis Group. https://doi.org/10.4324/9780429400469

Ifinedo, E., Rikala, J., \& Hämäläinen, T. (2020). Factors affecting Nigerian teacher educators' technology integration: Considering characteristics, knowledge constructs, ICT practices and beliefs. Computers \& Education, 146, Article 103760. https://doi.org/10.1016/j.compedu.2019.103760

Joo, Y. J., Park, S., \& Lim, E. (2018). Factors Influencing Preservice Teachers' Intention to Use Technology: TPACK, Teacher Self-efficacy, and Technology Acceptance Model. Journal of Educational Technology \& Society, 21(3), 48-59.

Kainat, Sultan, S., Ejaz, A., \& Sahar, W. (2021). Exploring Relationships among Use of TPACK Model and Teaching during COVID-19 at Secondary School Level. Psychology and education, 58(3), 2204-2214. https://doi.org/10.17762/pae.v58i3.4221

Khine, M., Ali, N., \& Afari, E. (2017). Exploring relationships among TPACK constructs and ICT achievement among trainee teachers. Education and Information Technologies, 22. https://doi.org/10.1007/s10639-016-9507-8

Koh, J. H. L., Chai, C. S., \& Tsai, C.-C. (2013). Examining practicing teachers' perceptions of technological pedagogical content knowledge (TPACK) pathways: a structural equation modeling approach. Instructional Science, 41(4), 793-809. https://doi.org/10.1007/s11251-012-9249-y

Koh, J. H. L., \& Divaharan, H. (2011). Developing Pre-Service Teachers' Technology Integration Expertise Through the Tpack-Developing Instructional Model. Journal of educational computing research, 44(1), 35-58. https://doi.org/10.2190/EC.44.1.c

Lee, C.-J., \& Kim, C. (2014). An implementation study of a TPACK-based instructional design model in a technology integration course. Educational Technology Research and Development, 62(4), 437-460. https://doi.org/10.1007/s11423-014-9335-8

Özgür, H. (2020). Relationships between teachers' technostress, technological pedagogical content knowledge (TPACK), school support and demographic variables: A structural equation modeling. Computers in Human Behavior, 112, Article 106468. https://doi.org/10.1016/j.chb.2020.106468 
Pamuk, S., Ergun, M., Cakir, R., Yilmaz, H. B., \& Ayas, C. (2013). Exploring relationships among TPACK components and development of the TPACK instrument. Education and Information Technologies, 20(2), 241-263. https://doi.org/10.1007/s10639-013-9278-4

Prion, S., \& Haerling, K. A. (2014). Making Sense of Methods and Measurement: Spearman-Rho Ranked-Order Correlation Coefficient. Clinical Simulation in Nursing, 10(10), 535-536. https://doi.org/10.1016/j.ecns.2014.07.005

Raper, R. C. (2018). The Relationship Between Secondary Teachers' Technological Pedagogical Content Knowledge and Technology Integration Factors (Publication Number 13422418) [Doctoral dissertation, Liberty University]. ProQuest Dissertations and Theses Global.

Raygan, A., \& Moradkhani, S. (2020). Factors influencing technology integration in an EFL context: investigating EFL teachers' attitudes, TPACK level, and educational climate. Computer Assisted Language Learning, Article 100034. https://doi.org/10.1080/09588221.2020.1839106

Rohaan, E. J., Taconis, R., \& Jochems, W. M. G. (2012). Analysing teacher knowledge for technology education in primary schools. International Journal of Technology and Design Education, 22(3), 271-280. https://doi.org/10.1007/s10798-010-9147-z

Santika, V., Indriayu, M., \& Sangka, K. (2021). Investigating of the Relations among TPACK Components of Economic Teacher Candidates in Sebelas Maret University (UNS) in 2020: A Structural Equation Modeling. Journal of Physics: Conference Series, 1808, 012029. https://doi.org/10.1088/1742-6596/1808/1/012029

Saudelli, M. G., \& Ciampa, K. (2016). Exploring the role of TPACK and teacher self-efficacy: an ethnographic case study of three iPad language arts classes. Technology, Pedagogy and Education 25(2), 227-247. https://doi.org/10.1080/1475939X.2014.979865

Schmidt, D. A., Baran, E., Thompson, A. D., Mishra, P., Koehler, M. J., \& Shin, T. S. (2009a). Survey of Preservice Teachers' Knowledge of Teaching and Technology. Retrieved from http://matt-koehler.com/tpack2/wp-content/uploads/tpack_survey_v1point1.pdf

Schmidt, D. A., Baran, E., Thompson, A. D., Mishra, P., Koehler, M. J., \& Shin, T. S. (2009b). Technological Pedagogical Content Knowledge (TPACK). Journal of Research on Technology in Education, 42(2), 123-149. https://doi.org/10.1080/15391523.2009.10782544

Shulman, L. S. (1986). Those Who Understand: Knowledge Growth in Teaching. Educational researcher, 15(2), 4-14. https://doi.org/10.3102/0013189X015002004

Sturak, K., \& Naughten, Z. (2010). The current state of Chinese, Indonesian, Japanese and Korean language education in Australian schools: Four languages, four stories. Education Services Australia.

Voogt, J., Fisser, P., Roblin, N. P., Tondeur, J., \& Braak, J. V. (2013). Technological pedagogical content knowledge - a review of the literature. Journal of Computer Assisted Learning, 29(2), 109-121. https://doi.org/10.1111/j.1365-2729.2012.00487.x

Walker, R. X. (2017). Assessing Teachers' Technological, Pedagogical, and Content Knowledge in Elementary Schools [Doctoral dissertation, Wilmington University]. Doctoral dissertation ProQuest Dissertations and Theses Global.

Wilson, C. (2013). Credible checklists and quality questionnaires: A user-centered design method. Morgan Kaufmann.

Yang, J., Wang, Q., Wang, J., Huang, M., \& Ma, Y. (2019). A study of K-12 teachers' TPACK on the technology acceptance of E-schoolbag. Interactive Learning Environments, 17(1), 1062-1075. https://doi.org/10.1080/10494820.2019.1627560

Zhou, Y., Chai, C. S., Liang, J.-C., Jin, M., \& Tsai, C.-C. (2017). The Relationship Between Teachers' Online Homework Guidance and Technological Pedagogical Content Knowledge about Educational Use of Web. The Asia-Pacific Education Researcher, 26(5), 239-247. https://doi.org/10.1007/s40299-017-0344-3 


\section{Copyrights}

Copyright for this article is retained by the author(s), with first publication rights granted to the journal.

This is an open-access article distributed under the terms and conditions of the Creative Commons Attribution license (http://creativecommons.org/licenses/by/4.0/). 